\title{
Empowerment In Marketing: Synthesis, Critical Review, And Agenda For Future Research: An Abstract
}

\author{
Hajer BACHOUCHE*, University of Paris-Est, Créteil, France, \\ hager.bachouche@gmail.com \\ Ouidade SABRI, University of Paris I Panthéon Sorbonne, Paris, France, \\ ouidade.sabri@yahoo.fr
}

\begin{abstract}
The literature on empowerment in marketing has grown exponentially in the 2000s. This article provides a comprehensive review of the concept of consumer empowerment, which in prior research has given rise to a variety of work with sometimes contradictory theoretical frameworks. Consequently, research fragmentation on the one hand, and the lack of integrative framework uniting all facets of empowerment, on the other hand, justify this research. We carried out_a review of more than 600 publications and books in various disciplines. As literature on consumer empowerment is traditionally published on Ebsco, this database was favored, then we've opened our study to other search engines (Elsevier, of Web of Science and Google Scholar).We conducted a research for articles with titles, keywords, or abstracts containing the terms "empowerment" and "consumer". From this research and identified references, we've selected 142 articles that we've studied in depth.

Firstly, building on scholarly insights from multiple literature streams, this paper identifies three facets of empowerment (bestowing power, gaining power, and as a subjective state) and structures extant marketing research according to it. As a matter of fact, marketing literature related to consumer empowerment can be classified according to the three facets of empowerment: the literature on public policy and collaborative management practices illustrates the process of delegation of power by local authorities or companies to consumers, while the process of gaining power from the consumers' perspective focuses on resistance to market structures. Finally, empowerment as a subjective state, called «psychological empowerment », refers to the consumer « sense of empowerment » related to an extension of its resources and an easier access to information by Web 2.0.

Secondly, an examination of foundational theories of power enables us to identify three models of power: the consumer sovereignty model, the cultural power model and the discursive power model. These three competing models deliver a different and complementary approach of the concept of empowerment and refer implicitly to the three facets of empowerment (bestowing power, gaining power, and power as a subjective state) discussed in this paper. Thirdly, linking the critical synthesis of empirical findings from marketing literature and theoretical approaches of power, we propose an integrated framework where future advancements on empowerment can be developed. This analysis reveals some limits associated with earlier research. We end by suggesting further directions of research to advance the theorization and empirical testing of empowerment.
\end{abstract}

References Available Upon Request 